\title{
How to Combine Professionalism with Modernisation in Today's Higher Education in Italy: A Case Study at Bologna University
}

\author{
Susi Poli \\ Department of Education, Practice and Society - UCL Institute of Education, University College London, UK \\ E-mail: susi.poli.14@ucl.ac.uk
}

Thomas Georgas (Corresponding author)

Institute of Education, University College London, UK

E-mail: tgeorgas@ioe.ac.uk

Received: 12-10- 2015

doi:10.7575/aiac.ijels.v.4n.1p.1
Accepted: 07-01-2016

Published: 31-01-2016

\begin{abstract}
This article contextualises the Higher Education in Italy from the outset by describing deeply rooted but accepted practices, such as the long-term dominance of academic groups in decision making - baroni and their 'court' - and also the widespread custom of 'Raccomandazioni' as the means to lead mechanisms of recruitment among "peers", being these academics or professional staff. However, assuming that forms of professionalism exist in this sector, our aim is to look for evidence of this professionalism; this will be done by looking at the most recent reform and at how this has been implemented within one of the professional communities. Later on, after taking into account the case-study of this group of professionals within the wider community, we explain why this can be regarded as a good practice of professionalism in HE management in the sector: in this case, modernisation and changes, backed by collective attitudes aiming at valorising domains of expertise, have been implemented across parts of the community and have also affected the whole institution. Overall, these collective understandings have facilitated the process of modernisation and its assimilation, since they have arisen from professionalism opportunely contextualised. Findings show how forms of professionalism are more likely to be found in small communities; and also how these, acting as communities of practice, can valorise one's knowledge and be driving forces at the time of any restructuring. Whilst, implications from this study aim to back further research into higher education management in Italy as well as into professional staff.
\end{abstract}

Keywords: Higher Education, Italy, professionalism

\section{Introduction}

A first insight into the Higher Education (HE) in Italy has its starting point in the excursus among newspapers' headlines, among others those issued in the last couple of years: "Italians are deeply anti-meritocratic", "Scratch my back" (The Economist), "Rise of a meritocracy offers Italy chance to revive stagnating university system" (Financial Times), "A Malaise hits Italian Academia" (Herald Tribune), "Italian University thinks globally, Battles locally" (The Chronicle of HE).

The Economist gives the first insight into HE in a special report issued in 2011: the label tells how"Italians are deeply anti-meritocratic" and the further section specifically on HE brings a more evocative title, "Scratch my back". The article stresses the custom of Raccomandazioni as a phenomenon well known and widespread across the sector; for instance, the report underlines how the job market for professorships has been deeply affected by unrewarding mechanisms of selection, with these public selections that are advertised just to cover decisions already taken on the list of "right" candidates to hire or promote. This practice is confirmed by the Herald Tribune, which in its article raises issues of masked competitions, where selections are more often led by professors disdaining any criteria of meritocracy. In addition, this is confirmed by an internal overview that see Raccomandazioni as the mechanism that has shaped the sector as a overturned pyramid of professorships, with a high number of full professors, a lower of associate professors and a rather small number of researchers (Perotti, 2008).

Being the custom of Raccomandazioni widely accepted and widespread, it is not likely to find evidence of professionalism in this HE sector. And just to see how this system of HE was originated, we look at Clark who claims how in order to understand a HE system "the effects of the different arrangements of authority are fundamental" (1983:131), and all deserve to be taken into consideration. Indeed, all across the continent systems work in this way, as "authority has been distributed traditionally in most of the academic systems of the European continent in a combination of faculty guild and state bureaucracy" (1983:125). In the next paragraph, we explore which factors have 
historically led to this system of HE in Italy and we also see how the recent university reform addresses the lack of professionalism in relation to the managing directors' community.

\section{Literature Review}

Looking at the origins and development of the sector, a "guildlike authority has predominated within the continental universities" (Clark, 1983:125) and Italy summarises all its features.

The sector has been perceived and then described in an unclear and perhaps confused way: the university system has been steered from a certain distance by the central government for years; this was the unchanged picture of the system even after fifteen years of reforms; in addition, thesector has maintainedmaintained some of its historical features, these including profound reluctance to change, slowness to react to external pressures, any link to societal needs and expectations. Reasons of this stagnation arise from the unbalanced allocation of authority in place/existing between academic guilds and the State, with the former acting as the coordinator of the system and much more influence than the latter (Clark, 2008; Capano, 2008). Among attempts of reform, the Ruberti reform dating back to 1989, stands for the first effort to change the whole system, as it was based on a State supervisory model of governance and on principles of institutional autonomy; but results showed how the powerful culture of academic oligarchs stopped any changes and so universities returned to an unchanged general framework (Capano, 2008).

In support of this, Clarks claims that "HE systems vary widely between dependence on authority and dependence on exchange" (1983:138) and that this coordination by academic oligarchy exists in other countries and not just in Italy (1983:140). However, his view was confirmed after comparing a number of national HE systems internationally and categorizing all these into the model of the Triangle of Coordination : in this comparative analysis, Italy was regarded as "well down toward the oligarchic extreme" and this arising both from its powerful national guilds as well as from weak market interactions within the sector (1983:143). This was the reason why the HE sector in Italy was regarded as characterised by the "triumph of particularism" (Clark, cited in Capano, 2008:499).

Following the Ruberti reform, a number of calls for modernisation of the whole sector were issued: these included the introduction both of forms of privatisation for state funded or public universities as well as of mechanisms of competition, which was the goal set by all prior reforms (Paletta, 2003; Perotti, 2008; Capano, 2008). It was acknowledged that only through cultural change and decentralisation of authority, it would have been possible to contrast any anti-meritocratic mechanisms led by academic guilds (Clark, cited in Capano, 2008:499).

This article is about the most recent reform, issued in 2010, which deals with one more attempt of modernisation of the sector. According to the reform, departments are thought to become the leading units and handle decisions on human and financial resources, and also on teaching and research issues. Furthermore, this impacts on forms of governance and on public selections for professorships, among others.

However, this reform was perceived as a bureaucratic attempt of modernization from the outset; indeed, for any form of modernisation in public institutions, we should have a frame of reference and, in this particular case, take into account how Newman has categorised models of governance and how these go through restructuring and modernisation. In mapping a conceptual framework consisting of four models of governance, the author goes from the hierarchical oriented, characterized by bureaucratic power and vertical patterns of relationships, to the rational goal model, dominated by managerial power dispersed across a wide range of units. Despite its apparent devolution of power, this latter model reflects a rather centralised approach, a blend of vertical and horizontal relationships. Other two models refer one to the open system model, oriented towards network forms of interaction with power really dispersed, dynamic relationships, focus on innovation; and the other to the self-governance model, based on building sustainability and fostering relationships of interdependence and reciprocity, so to strengthen the capacity of communities and user groups (Newman, 2001:33-35).

In conclusion, looking at the Gelmini reform and at Newman's models, we see how the rational goal model seems the most likely to be applied to modernisation at Bologna university, and we will show what this implies laterlater in this paper.

\section{Research Design and Methods}

Methodologically, we use documentary analysis to show why this reform was perceived as a bureaucratic attempt of modernisation from the outset; in doing so, we look at how the university has dealt with the professional community more affected by changes arising from the reform, that is that of departments' managing directors; and then we rely on biographical analysis to show how a restricted group of these professionals, set up prior to the restructuring, has been ready to cope with modernization. Theoretically, we reflect on two definitions of professionalism: one is the definition of 'bounded' professionals as the overarching definition for all those within the professional community; and the other of 'craft' to refer to features shown by those in a restricted group of these professionals.

Therefore, after describing the overall framework and some of the main issues impacting on the sector, our research questions aim to explore: first, how the Gelmini reform deals with professionalism within Bologna university and, specifically, within one of its professional communities, made up of departments' managing directors; secondly, which conceptual definitions best describe professionals in the whole community and, more specifically, those grouped in a restricted part of the overall community and why each definition fits these colleagues; thirdly, looking for cases of 
professionalism in the university, we shed light on how the practice of understanding, first, and contestualising professionalism, then, can help in the process of modernising the community and perhaps the whole university.

The analysis begins with the description of who are those in our professional community: this is made up of managing directors who currentlycurrently hold a post in a higher number of departments (pre-reform); since they aspire to be confirmed as post-holders, they are asked to go through a selection process which aims to assess one's expertise and confirm the post just for a smaller number of them in restructured departments (post-reform).

This community, therefore, feels under pressure because of this assessment and overall deeply affected by the reform and its changes. Assuming that this community might be characterised by profound reluctance to change, which may look astonishing for such an innovative sector but that is common internationally (Clark, 1983:182), we will see how modernisation impacts on the professional group by looking at documents and cases at the institutional and at the community level.

Therefore, we deal with the three research questions by looking at:

- how the Gelmini reform impacts on the community of managing directors by looking at the documents explaining the procedure of assessmentassessment, since this aims to identify post-holders in reformed departments, as a first-stage analysis;

- the second stage will look for two definitions of what it means to be (a) professional within this community in today's sector and why the two definitions chosen are anthitetic but can be representative of the level of differentiation in expertise and attitude within the whole community;

- whilst the third stage will focus on one of these definitions and on the case-study of a restricted group of colleagues, to make the point that forms of professionalism based on valorising one's expertise can act as the driving force within the wider community.

About methods and methodologies, we have adopted a case-study method looking at the institutional, community and sub-community level (Tight, 2003:202); this method is commonly used for researching into higher education (ibid, 2003:185). Whilst the methodology will deal with documentary and biographic analysis; official and unofficial documents coupled with real-life experiences will enable us to investigate forms of professionalism within the university community.

\section{Analysis}

Despite being a leading University which received its Charter directly from Frederick I Barbarossa in 1158 and the first university in the Western world as well as the venue of the Bologna Process, the University seems more oriented to reply features of the whole sector than to modernise its own environment, and we will early explain the reasons.

Bologna University set up its Multi-Campus organisational model in 1995, resulting in the aggregation of five regional campuses spread across the region; it counts approx. 85,000 students and over 6,000 staff, both academic and administrative personnel. From this snapshot, we spot features of "super-complexity" at Bologna university, where this stands for the segmentation of the whole into basic units, the one which Clark would define the "elaborated developmental periphery" (2004:85), each with its degree of influence in driving individual behavior and institutional strategies. "Supercomplexity is, therefore, not just hyper-complexity ... it is a higher order form of complexity. It is that form of complexity in which our frameworks for understanding the world are themselves problematic ... in which our very frameworks are continually tested and challenged. This supercomplexity is the world in which we all live" (Barnett, 2000:76).

Thus, as earlier said, the first impression arising from the Gelmini reform looks like a bureaucratic attempt of modernization and this is the reason why we claim so. Indeed, even whether the reform has been communicated as a fair and holistic attempt to re-shape the whole organisation, the restructuring affecting Bologna University aims to follow the overall goals stated nationally without any attempt of contextualising the reform and its changes. Furthermore, in this reformed structure, departments stand as the main units; in addition, under the new governance model, decisions are expected to be in the hands of the university governance with no evidence of any "communityuniversity engagement" of more actors along the decision-process (Watson, 2007:3), such as those involved within Clark's "steering core" (Clark, 2004).

This impression finds confirmation in the university document titled 'Leading stages and actions for the organization of services and the optimized allocation of human resources within the restructuring process affecting teaching and research units at Bologna University', issued in June 2011.

Concerning the documentary analysis, in handling official documents delivered by the University to communicate stages of the reform, we have applied criteria of internal criticism (Bell, 2010:135). Thus, we have tested how "unwitting evidence" plays a more powerful role than any form of witting evidence; the former to be intended as what can be read in a document which goes behind any form of evidence clearly written in that document (Bell, 2010:131). Overall, this document deals with challenging and innovative issues and also provides a number of information about the stages of assessment and selection for the posts of managing director in 33 restructured departments; in addition, the document describes further opportunities primarily for those failing in the assessment but for the post-holders too and these go from intra-university mobility to professional development. 
In so doing, the document shows, on the one hand, its witting side by relating modernisation with several opportunities of mobility and professional development for all those involved in the assessmentassessment; on the other, looking at its unwitting side, it seems to see a call for promoting cultural change across the community. Indeed, professional development and mobility are shown as the vehicle to lead departments to be overall more competitive and researchoriented internationally, and also able to rationalise financial resources, all this stressed in the witting evidence part of the document. Furthermore, the three objectives above are coupled with opportunities of professional development and this seems to confirm the unwitting intention of finding ways to push for cultural change; as a result and further element of analysis, this stress on the intention can be a claim that there have been deficiencies in managing departments and the reason why decisions have been taken sometime by the university and its Centre regardless of autonomy accorded to departments; this latter is again unwitting evidence.

However, professional development cannot be the only way to promote changes, since this has been adopted in recent past with no effects and the reason may be that staff is already given and not easily modifiable in their background of expertise (Paletta, 2003; Perotti, 2008). Just among deficiencies of the Italian system, Clarks just stresses the "lack of institutional focus for the selection and training of competent civil servants" (1983:198), so to confirm that only the latter cannot be enough with no fair and appropriate selection carried out before. On the contrary, professional managers should be selected with care, with training as important as the one for young academic staff, as successful organizations are the ones that have been able to recruit and retain good staff (Shattock, 2003:179; Watson, 2007:141).

In the next sectionsection, we will see how the process of modernisation impacts on the professional community and why.

\subsection{Modernizing the Professional Community}

The following stage of documentary analysis refers to looking at the document entitled to Restructuring Departments: the Pathway to select the Managing Director in new Departments, as the call for assessment of all the current positionholders. After shaping the "best professional profile" in the document, the assessment aims to evaluate competences of the whole cohort of candidates in order to align the best profile with that of 33 candidates to-be-selected; methodologically, this process shows features of a new type of assessment, never run in the sector, which stands in between a promotion - which should be the only way to access higher positions in the public sector in compliance with the Constitution - and an appraisal, such as that carried out annually at UCL, as "founded on the belief that all members of staff have a right ... to feel valued and to receive feedback on their contributions to the work of their departments and UCL" (UCL, 2011). Thus, the professional profile set in the document shows a wider range of skills and a higher level of expertise regarded as required by the position; as a result, this reformed position seems to call for integrating skills from post-holders.

Just this integrated set of skills is what we aim to focus on as the strength shown by a restricted group of colleagues, and this stands for our case-study; we will describe who these colleagues are after describing characteristics of all those belonging to the whole community.

The professional community has been perceived as highly differentiated in relation to how administrative practices have been run; indeed, even if all these procedures comply to the same set of university regulations, they can be performed rather differently; and it is not infrequentinfrequent that they can be interdicted and this depending on a particular department or on who handles the procedure. But the same level of differentiation characterises colleagues within the community as well, since these may show their reluctance to change and see any change only as threat; they may have an individualistic attitude; coupled with a restricted capability of sharing good practices, among the main ones. We know how "the resistance to change is a matter of power for a large stratum of people and how when a possible change is admitted to consciousness and even debated, it is seen as a threat to that stratum's rights and privileges" (Clark, 1983:214).

All this appears to be a cultural challenge under the ongoing restructuring, since it calls for overarching changes and for a deep modernisation affecting attitudes of the whole community of post-holders.

Which definitions can describe these colleagues as professionals in today's HE?

\subsection{Dealing with a first definition of Professional - Unbounded professionals by Whitchurch}

After describing those in the whole community, we assume that a professional identity within the community does not exist yet, since this would consist of commonality, shared sets of practices, collective approach to new regulations and capability to deal with tricky issues. Just according to Social Identity Theory, a part of an individual's identity comes from the inclusion in a social group and the more an individual identifies with a group the more such membership shapes her attitudes and behaviors (Showunmi, 2011); this doesn't seem the case within the community under investigation. Thus, we see a number of colleagues more aligned with the definition of bounded professional, "the disinterested professional or civil servant ... associated with maintaining the requirements associated with a role culture ... so to shape their own space differentiated from others' space" (Whitchurch, 2006:14-16). These individuals are more often characterised by a strong resistance to any change - since this may cause a loss of privileges - and by looking for forms of adaptation to these changes, when happening, or of their contestualisation/valorisation.

According to Whitchurch, professionals come to be categorized on the basis of approach with existing structures as well 
as of their attitude to respect boundaries among functions and roles, so that main identities refer to: bounded as the old style-professional mainly shaped around the "definition of own role in terms of maintaining well-defined processes as well as reluctant to deviate from core functions"; cross-boundary are performers using "boundaries to construct and modify their identities ... actively work across a number of locales to contribute to institutional capacity building"; unbounded professionals show "a sense of being keyed into networks that facilitate the exchange of information and intelligence that can be invested in the institution ... acting as a pathfinder"; whilst blended professionals have "an ability to work in ambiguous space between professional and academic domains ... actively using a mixed background to advantage" (Whitchurch, 2006:16-25).

Hence, in dealing with an assessment affecting their professional profile, colleagues in the community feel under the pressure of modernisation and so threatened by changes. Therefore, after assuming that most of the colleagues into the community are bounded professionals for the reasons above, we will look for colleagues acting differently and for a second definition of professional. These definitions range from extended to restricted professionalism, as well as from activist to distressed; again, from oppressed, to traditional or collaborative professionalism (Cunningham, 2008). But all these definitions cannot be detached from the overall context we are dealing with, of the HE sector in Italy and of supercomplexity at Bologna university; therefore, we cannot miss to include the main features of the HE sector, which, as part of the wider public sector, appears characterized, on the one hand, by cases of absenteeism and low-rate of commitment; on the other, by unfair wages and low-rate of recognition of own being professional even for best performers (Clark, 2008; Capano, 2000; EURISPES, 2007). And all these features seem to confirm that the nature of being a professional in this community in today's HE mainly call for a definition vocational and engagement-driven professionalism, so we will look those among colleagues showing these must-have sort of features.

Where does evidence of professionalism lie within the community, so to explain how modernization may be usefully combined with professionalism?

\subsection{Communities of Practice in Higher Education - How groups of individuals work}

In this paragraph, we use a biographical approach to tell the story of a sub-community within the wider community and how this is characterised by colleagues performing in a collective way based on sharing of expertise and practicalities, in the way communities of practice normally do.

Communities of Practice (CoPs) are groups of people who share a concern, a set of problems, or a passion about a topic, and who deepen their knowledge and expertise in this area by interacting on an ongoing basis. It can be the case of people who don't work together every day, but who meet because they find value in their interactions, so to share information, insight, advice; this is the way chosen to help each other to solve problems, and it can come to create tools, standards, manuals. CoPs have three distinctive elements, the domain of knowledge, and the community of people who care about this domain and the shared practice developed to be effective in their domain (Wenger et al., 2002: 27-29). Hence, they accumulate knowledge as well as they become informally bound by the value found in learning together.

Some communities of practice in HE exploit the findings of an International project funded from the Australian Government (ALTC) titled "Identifying, building and sustaining leadership capacity for communities of practice in higher education": the core of the project focuses on formal and informal programs for professional development, and suggests that well-led and structured CoPs are successful in leading change and transforming teaching and learning practice. One more experience of $\mathrm{CoP}$ lies in Europe at the Hogenschulen based in Utrecht and explains how internal/external developments in HE have driven and shaped new pathways of staff professionalization; the experience explains a way of learning and working applied to educational innovations, in which learning develops along three different strands at the same stage (on the content of learning, on the social dimension of group, on the process itself of learning), so that benefits range from the Organizational to the Personal dimension (Hezemans and Ritzen, 2005).

Concerning the biographical approach, this case-study of CoP does not take into account the whole professional community, not perceived as a full-requirement CoP since, despite the three fundamental elements, misses the element of practice, to be intended as the specific knowledge that the community develops, shares and maintains (Wenger et al., 2002:27-29). In fact, as early said, professionalism among colleagues varies among departments as well as practices appear to be much diversified and therefore not shared, although all these comply with university regulations.

In this sense, on the one hand, the whole community cannot fit the definition of CoP, as "members of that community have developed a shared way of going on in the practice. The practice itself is characterized by rapid flows of information" (Wenger, cited in Scott et al. 2004:59). On the other hand, we aim to consider a restricted group of colleagues consisting of six people, named SAD Group, with SAD as the acronym of the overall community; this group was set up in 2008 and can fulfill features of a community of practice since its common domain deals with practicalities of management, but also with issues arising from day-to-day workloads, and then with new policies and regulations clashing with norms, among others. To effectively face all this, the SAD group relies on planned meetings with agendas/minutes, as well as on meetings on-demand, so that "when a problem occurs, its content is understood in terms of an agreed framework, and discussion of this framework is implicit" (Wenger, cited in Scott et al. 2004:59). As a result, this CoP acts in a collective way, as an informal community made of professionals who have selected each other among peers as the "best performers" in different subjects, so to cover, as a whole, all the fields of expertise required by the position of managing director in departments. They have themselves able to study in depth and elaborate complex 
but comprehensive documents on main policies, to analyse and then summarise tricky points in new regulations, to raise burning issues arising from the application of new regulations and stress whenever these overlap with practicalities. They can then liaise with central offices and offer specialised advice if required; and they can talk directly with the Head of Administration (HoA) and make the voice from the community heard; lastly, they can also be proactive in proposing own interpretations and solutions.

Overall, the role played by this informal sub-community has been internal and external: on the one hand, they have gained awareness of their professional identity and strengthened knowledge of other fields of expertise; on the other, they have built up a repository of knowledge in practice and become the contact point with central and specialised offices and the HoA (the university Centre) since the holders of pockets of expertise not commonly found at the periphery level, so in departments. Specifically, the biographical part of the analysis has been carried out by looking at minutes and main documents issued by the group, coupled with analysis of notes taken at meetings and also observations of attitudes and critical thinking applied to particular situations.

As the repository of this high level of expertise, this CoP has an understanding of tricky issues and the capability to cope with problematic situations, "the agreed framework" quoted above where discussion of problems within the framework is implicit. Furthermore, it may proceed with further improvements and actions, such as those of diagnosing recurring problems, analyzing the knowledge-related sources of uneven performance, as well as coordinating unconnected activities addressing a similar knowledge domain (Wenger, 2002:14-16).

We have, therefore, assumed that most of the colleagues within the managing directors' community only show features of bounded professionals and then we have sought for cases of colleagues performing differently, such as those we came across in the SAD group. Later on, after considering the main features of the HE sector and what lacks in it, we have assumed that professionalism should evoke the meaning of Craft, this standing for professionalism as vocation and as the desire to do something well, for its own sake (Sennett, 2008:145). In the paragraph that follows we will give the second definition of being (a) professional in today's HE in Italy and this will arise from conceptualising the term Craft.

4.4 Craft as the second definition of being (a) professional in the sector-Being collectively engaged and doing things 'for its own sake, for pleasure, for the community'

The first image coming to mind when thinking about craftship is the inside of a carpenter's shop with an elderly man surrounded by apprentices; the carpenter representing the prototype of the craftsman dedicated to good work for its own sake with labor not simply as a means to another end (Sennett, 2008:19-20). The opposite model shows low-rate degree of performance of poorly and unmotivated soviet workers (ibid, 2008:29); thus, the drivers for good results lie in motivation and in aspiration for quality, with motivation much more important than talent in consummating craftsmanship. Hence, the reward only derives from a sentiment of competence deriving from slow learning and on habit (ibid, 2008:265). All these features seem to call for a concept of professionalism in which the term Craft means vocation but also raises "the special human condition of being engaged" (ibid, 2008:20): for its own sake, for pleasure, for the community and, perhaps as in our case, for the whole university.

Within the SAD group all the notions of Craft seem to be met. Vocation and desire to do something well, along with motivation and aspiration as drivers of quality work; labor as not simply a means to another end, so based on slow learning and on habit. All these notions seem incorporated in the SAD group, since they show to address issues for its own sake as well as for the benefit of the whole professional community once acting as the contact-point with the university Centre.

Craft, in this meaning, also raises the condition of being engaged within the modernisation of the university; it seems therefore to see the same engagement applied in Clark's "strengthened steering core", the self-governance model strengthening the capacity of all the partners involved ... to generate momentum and take responsibility for actions and outcomes" (Newman, 2001:116); to the extent of realizing the "community-university engagement" (Watson, 2007:3) that seems to visualise that kind of "third-order engagement" between the university and its members (ibid, 2007:139).

\section{Conclusion}

In conclusion, we have pictured some features of the HE sector in Italy and then listed which features characterise the professional community under examination; in doing so, we have seen how most of these features mirror the characteristics of the whole sector, among others: reluctance to change, attempt to preserve the status quo, individualistic and rather formal approach in performing also differently along the frame of procedures.

Overall, we have looked at efforts, from the university and from a small group within the whole community, to professionalise the community or to put professionalism into practice. Specifically, we have analysed, first, the impact of this reform on the whole professional community through the investigation of main documents on theassessment of managing directors; we have, secondly, conceptualised definitions of professionalism as applicable to the whole community; thirdly, we have used biographical experiences and shed light on a case-study which shows how professionalism in a restricted collectivity, able to valorise its range of expertise, may support or promote modernisation both at the community and at the university level.

The CoP was set up in 2008, so it was already contestualised in a pre-reform environment; as a result, it was prepared for re-contestualising its professionalism under the restructuring. This has been one of the strengths of this group to rely 
on.

Overall, individuals in the SAD group have understood their grounds of expertise and valorised these at the time of the reform; they have then shared their knowledge in the practice of the ongoing process of modernizing the community and the university. In doing so, they have shown that collective attitudes are as much likely as individualistic ones in the sector; summing up, they have come up with this $\mathrm{CoP}$ and its strength has been not just valorising or contestualising one's expertise but to look for forms of professionalism that may be beneficial for those within the whole community.

In fact, these SAD colleagues shape a second definition of professional within the wider community and the sector, which refers to the attitude of the 'craftman' or of the 'craftwoman': this case-study shows therefore how strengths can be found in collective attitudes, understanding of one's expertise and valorisation, and putting reforms into the context of this collective understanding. Looking at what they have done so far, it seems to us that this SAD CoP has already been impacting on the community as well as on the university, since the SAD colleagues have developed that craft intimacy which stands for strong interaction around a common set of problems (Sennett, 2002:122) but also that deep sense of identification with a group which allows to shape attitudes and behaviors (Showunmi, 2011). Moreover, the SADs have succeeded in valorising, first, and connecting, then, local pockets of expertise from different departments, and this stands for contextualising one'sone's professionalism in the light of the reform.

As a final comment, restructuring the university seems to impact on colleagues from the wide community and their attitude - conceptually defined as 'bounded' professionals - more than on the SAD group. We can, therefore, claim that these SAD colleagues have found the way to steer change towards a collective idea of professionalism, even whether the university was backing a more individualistic approach by providing opportunities of professional development and staff mobility; and then how evidence of professionalism can be found in the sector once investigated; and lastly how, even in this apparently unchangeable HE sector, there are ways of preparing for modernisation and also of purposely combining professionalism with this modernisation.

\section{References}

Alma Mater Studiorum University of Bologna (2011). Linee di Intervento per l'Organizzazione dei Servizi e il Miglior Impiego delle Risorse Umane nell'ambito della Riorganizzazione delle Strutture di Ateneo (Leading stages and actions for the organization of services and the optimized allocation of human resources within the restructuring process affecting teaching and research units at Bologna University) Governing Council document can be found at www.unibo.it

Alma Mater Studiorum University of Bologna (2011), Riorganizzazione dei Dipartimenti: il Percorso di Individuazione del Responsabile Amministrativo nelle Nuove Strutture (Restructuring Departments: the Pathway to select the Managing Director in new Departments). Document issued by the head of administration that can be found here: www.unibo.it

ALTC (2010). "Identifying, building and sustaining leadership capacity for communities of practice in higher education". From Australian Government Office for Learning and Teaching in Grants and Projects: http://www.altc.edu.au/project-identifying-building-and-sustaining-leadership-capacity-communities-practice-highereduc

Barnett, R. (2000), Realizing the University. Buckingham: SRHE \& Open University Press.

Bell, J. (2010), Doing Your Research Project. Fifth Edition. Buckingham: Open University Press.

Capano, G. (2000), L'Università in Italia (The Higher Education Sector in Italy). Bologna: Il Mulino.

Capano, G. (2004). Un po' di coraggio per cambiare l'Università (Some Bravery to Change the University). Bologna: Il ulino, 54(5), 888-898.

Capano, G., and Gualmini, E. (2006), La Pubblica Amministrazione in Italia (The Public Sector in Italy). Bologna: Il Mulino.

Capano, G. (2008), Looking for Serendipity: the Problematic reform of Government within Italy's Universities, Higher Education, 2008, 55, 481-504.

Capano, G. (2008), The Crisis of Academic Power in Italy (La Crisi del Potere Accademico in Italia). Bologna: Il Mulino.

Clark, B.R., (1983), The Higher Education System. University of California Press.

Clark, B. R., (2004), Sustaining Change in Universities. Buckingham: SRHE \& Open University Press.

Clark, B. R. (2008), On Higher Education. Selected Writings, 1956-2006. The Johns Hopkins University Press.

Cunningham, B. (2008). Exploring professionalism. London: IOE University Press.

Dinmore, G. (July 29 $9^{\text {th }}$, 2008). Rise of a Meritocracy Offers Italy Chance to Revive Stagnating University System. Financial Times, p. 2.

EURISPES (2007). La Pubblica Amministrazione in Italia Annual Report 2007 (The Public Sector in Italy).

Hezemans, M. and Ritzen, M. (2005), Communities of Practice in Higher Education, in IFIP International Federation for Information Processing, 182/2005, 39-46. 
Newman, J. (2001). Modernizing governance: New Labour, policy and society. London: Sage.

Newman, J. (2005), Remaking Governance. Bristol: The Policy Press.

OECD (2010). Education Higher Education Structure in Italy 2010. OECD report.

OECD (2010). Focus on Higher Education in Europe 2010: the Impact of the Bologna Process. OECD report.

Paletta, A., (2003), Il Governo dell'Università (The University Governance). Bologna: Il Mulino.

Perotti, R. (2008), L'Università Truccata (The Faked University). Bologna: Gli Struzzi Einaudi.

Povoledo, E. ( March 23th, 2008). A Malaise hits Italian Academia. Herald Tribune International Edition p. 3.

Prideaux, J. (June 11 $\left.{ }^{\text {th }}, 2011\right)$. Oh For a New Risorgimento. The Economist. Special Report, pp. 9-10.

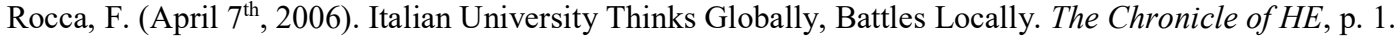

Scott, D., Brown, A., Lunt, I., Thorne, L. (2004), Professional Doctorates - Integrating Professional and Academic Knowledge. London: SRHE \& Open University Press.

Sennett, R. (2008), The Craftsman, London: Allen Lane.

Shattock, M. (2006), Managing Good Governance in Higher Education. Buckingham: Open University Press.

Shattock, M. (2003), Managing Successful Universities. Buckingham: Open University Press.

Showunmi, V. (2011), Does Identity have a Role to Play within the Context of Professionalism? in FoP module October 2011.

Tight, M. (2003), Researching Higher Education, The Society for Research into Higher Education.

University College London UCL (2011). Appraisal, Review and Development Scheme: http://www.ucl.ac.uk/hr/docs/staff_review_development.php

Watson, D., (2007), Civic and Community Engagement. Buckingham: Open University Press.

Watson, D. (2009), The Question of Morale. Open University Press.

Wenger, E., Mc Dermott, R., and Snyder, W. M. (2002), Cultivating Communities of Practice: a Guide to Managing Knowledge, Harvard: Harvard Business School Press.

Whitchurch, C. (2006), Professional Managers in UK Higher Education: Preparing for Complex Futures. London: Leadership Foundation for Higher Education.

Whitchurch, C. (2008), Shifting Identities, Blurring Boundaries: The Changing Roles of Professional Managers in Higher Education. London: IOE Centre for Studies in Higher Education.

Whitchurch, C., \& Gordon, G. (Eds.). (2009). Academic and professional identities in higher education: The challenges of a diversifying workforce. London: Routledge. 